\title{
Resilience and collapse of artisanal fisheries: a system dynamics analysis of a shellfish fishery in the Gulf of California, Mexico
}

\author{
Newton Bueno · Xavier Basurto
}

Received: 25 February 2009/Accepted: 17 August 2009/Published online: 12 September 2009

(C) Integrated Research System for Sustainability Science, United Nations University, and Springer 2009

\begin{abstract}
Analyzing different pathways by which socialecological systems can loose resilience and enter trajectories of collapse constitutes an important aspect of our quest towards understanding resource sustainability. This paper's goal was to better understand the effect of a particular class of disturbance-the accumulative effects of routine stressors-in the context of marine social-ecological systems. To that effect, we built a system dynamics model using empirically collected institutional and biological field data of an artisanal fishery in the Gulf of California, Mexico. Among our findings, we identified different scenarios under which even very small endogenous changes in the relationship between ecological and institutional variables can send a seemingly resilient system into a trajectory of collapse. We discuss why these types of disturbances are so difficult to prevent and be identified by the users of the resource, as well as potential strategies to address these challenges.
\end{abstract}

Keywords Common-pool resources - Resilience · System dynamics - Gulf of California, Mexico . Artisanal fisheries

\footnotetext{
N. Bueno

Federal University of Viçosa, Viçosa, Brazil

X. Basurto

Workshop in Political Theory and Policy Analysis,

Indiana University, Bloomington, IN, USA

X. Basurto $(\bowtie)$

Duke Marine Lab, Nicholas School of the Environment,

Duke University, Beaufort, NC, USA

e-mail: xavier.basurto@duke.edu
}

\section{Introduction}

Recent concerns of global fisheries overexploitation has focused research towards understanding sustainability and the collapse of marine social-ecological systems (Hilborn et al. 2003; Myers and Worm 2003; Salas et al. 2007). The application of the concept of resilience as a proxy for sustainability in social-ecological systems is gaining popularity among scholars of different persuasions (Perrings 1998; Adger 2000). Resilience is the amount of disturbance a system can absorb without shifting into an alternate regime (Holling 1973). The loss of resilience takes place when a state variable of the system crosses a critical quantitative threshold, either through a surprise-driven crisis or a piece-meal process (Carpenter and Gunderson 2001; Folke et al. 2002). When a fisheries social-ecological system surpasses a certain threshold, the regeneration rate is overcome by the harvest rate and, thus, the resource stock starts to endogenously decrease with eventually negative consequences for the social-ecological system.

Previous works have considered the loss of resilience of social-ecological systems mostly as a consequence of surprise-driven crises that affect the systems' agents' ability to cope with sudden perturbations (Carpenter et al. 2001), such as in the case of unusually severe droughts (Weiss and Bradley 2001), sudden increases in fishing effort (Jackson et al. 2001), or environmental disturbances occurring in the conservation phase of social-ecological systems' adaptive cycles (Holling et al. 1995).

While work that has documented surprise-driven crises has been important in helping develop an understanding of the dynamics of social-ecological systems, the role of piece-meal processes, that is, the incremental effect of nonnovel or routine factors, may play in the loss of resilience of social-ecological systems has received comparatively 
less attention (Rudolph and Repenning 2002). As an example of a piece-meal-produced crisis-thereafter, quantity-induced crisis-is the well-documented case of a Sri Lankan fishery as described by Alexander (1977). Fishers in the fishing village of Mawelle developed an ingenuous system to control the intensity of their fishing effort in the face of a population increase (a state variable of the system). They deployed their nets in a very orderly sequence in order to allow equal access to catches during the year. This system worked well as long as the population did not exceed a certain threshold. But the system's success led it to fail due to the quantity effect. While there were only twenty nets, a man received 1/160th of the annual catch. That was because at least eight men were needed to haul in a net and, therefore, it was divided into eight ownership shares. But, if after a man's death his two sons took joint ownership of the net, they each received only $1 / 360$ th of the annual catch. To avoid the collective action problems caused by the above endogenous dynamics, legislation was enacted by the national government requiring the registration of beach-seines throughout the country. This solution was very ineffective in controlling the entry of new fishers, which drove the system to a situation of virtual collapse in which, at some point, more than 100 nets were being deployed at very low levels of productivity.

In order to address this gap in the literature, we created a simulation model based on the Seri callo de hacha $(\mathrm{CDH})$ fishery in the Gulf of California, Mexico (Basurto 2005, 2006, 2008) to illustrate how the incremental effect of stressors can be, in certain cases, sufficient to lead even a seemingly resilient artisanal fishing social-ecological system to collapse. We chose this particular fishery because it has been sufficiently documented and constitutes an example of resilience to overfishing as compared to other socialecological systems in the region (Moreno et al. 2005).

In its starkest form, the model assumes that the stock of $\mathrm{CDH}$ decreases from being extracted by Seri fishers and increases through the regeneration of the biological population of $\mathrm{CDH}$. The resilience of the fishery would be jeopardized when the rate of extraction becomes higher than the regeneration rate. While apparently obvious, the dynamics of this class of models may be counter-intuitive, depending on the values assumed for critical parameters, like the intrinsic growth rate of the resource base (Brander and Taylor 1998) or the degree of non-linearity of key behavior functions (Anderies 2000).

We use a simulation model in this paper not as an attempt in validating a particular explanation of the world in the sense of establishing truthfulness, but, rather, as a procedure to identify hidden patterns and to learn about complex system dynamics (Sterman 2000). In particular, we will show that building and simulating a system dynamic model for the Seri fishery, even though parameters refer to a context-specific case, can help to identify a kind of general time-signature for quantityinduced crises, which can affect other fishing commonpool resource systems (Morecroft 2007; Randers 2007).

The rest of the paper is organized as follows. First, we provide a brief background of the case study, followed by the system dynamics methodology and the results of the simulations highlighting the argument that apparently resilient systems, like the Seri fishery, can easily fall into a path of loss of resilience through non-novelty crises. In the Discussion section, we discuss the results of the simulations, paying particular attention to the momentum built in the system, that is, the degree in which a system like the Seri fishery can be hit by a quantity-induced crisis.

\section{Background}

The Seri fishery stands out among other fishing communities in the Gulf of California region for their ability to govern and conserve their fishing resources without collapsing (Basurto and Ostrom 2009). In comparison, the neighboring fishing town of Kino Viejo (KV) (Fig. 1) located immediately south of the Seri-using the same harvesting technology and exploiting the same species, was unable to do the same (Moreno et al. 2005). Callos de hacha (CDHs) are sessile bivalve mollusks that live buried in

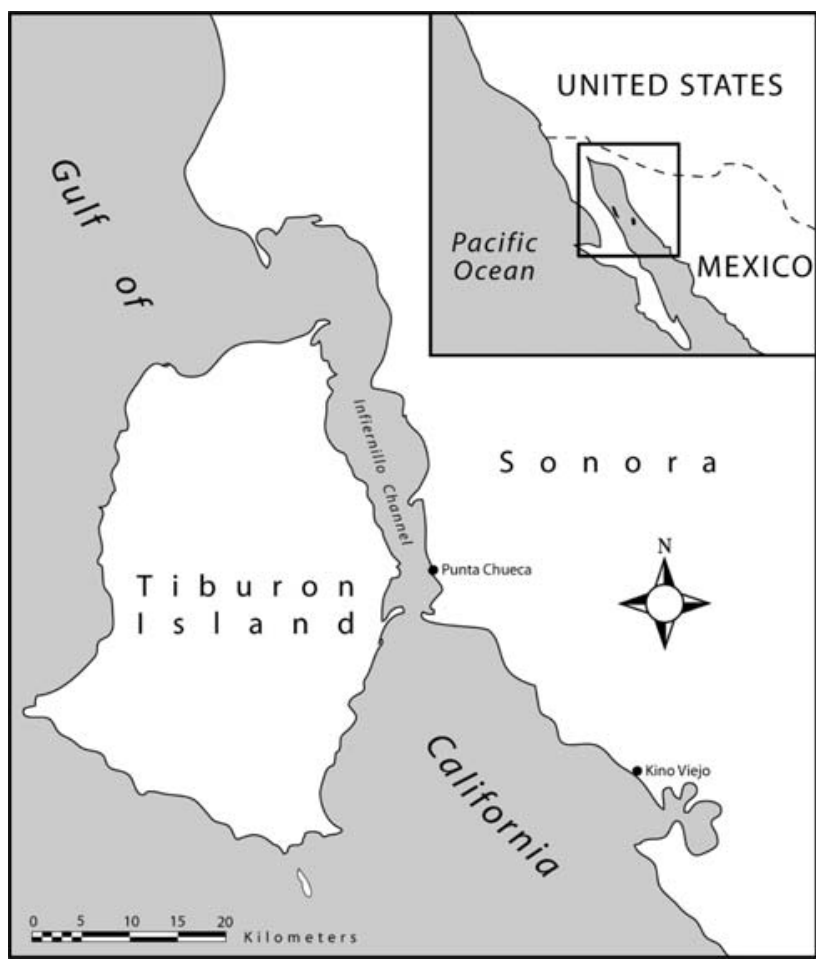

Fig. 1 Location of the Infiernillo Channel, the Seri PC Village, and the mestizo Kino Viejo (KV) village 
sandy bottoms. Atrina tuberculosa is the most important $\mathrm{CDH}$ species in the region and is harvested for its edible adductor muscle because it brings high prices to the national market (Basurto 2005). Fishers dive to unbury CDH using a rudimentary underwater breathing apparatus connected through a long hose to an air compressor mounted atop a fiberglass outboard motor boat. Typically, a fishing team consists of one or two divers and two crew members who motor the boat and handle the catch on the surface. The $\mathrm{CDH}$ fishery is one of many Mexican small-scale fisheries not actively regulated by the federal government and managed by the Seri under a common property regimen. The entire Seri CDH fishery takes place inside of the Infiernillo Channel, a long (41-km), narrow, and shallow (average depth of $5.5 \mathrm{~m}$ ) body of water that runs south to north and is flanked on the west by Tiburon Island, Mexico's largest, and to the east by the continental coast of the Mexican state of Sonora (Fig. 1). The Infiernillo Channel constitutes a de facto exclusive fishing zone for the Seri of the PC village.

The channel is widely believed to hold the most abundant $\mathrm{CDH}$ banks in the region and the entire Seri $\mathrm{CDH}$ fishery takes place there. Given outsiders' demand to fish inside the channel, the Seri have designed a number of rules to grant access to outsiders which they can monitor and enforce at a low cost to the community (Basurto 2005). One rule specifically dictates that, for a non-Seri fishing crew to become an authorized entrant, a member of the Seri community must be hired as part of the fishing crew. This rule allows granting access rights to generate economic benefits to different members of the Seri community, given that it is customary to share the catch among all of the members of the fishing crew. This rule also allows Seri to monitor the compliance of another rule dictating that fishers must not fish in culturally important areas, such as Infiernillo Channel's sandbars exposed at low tide intervals. Sandbar harvesting constitutes a subsistence practice hundreds of years old, where $\mathrm{CDH}$ harvesting takes place without the need for diving and is noteworthy for the active participation of members of the Seri community such as women, children, and elders. The most important sandbar harvesting events can become large communal gatherings. To successfully harvest bivalves in sandbars, members of the community must rely on detailed ecological knowledge if harvesting is to take place before the water has covered them again. This knowledge allows community members to notice differences in abundance from one harvesting event to the next. If they notice significant or unexpected differences in abundance, they usually think (justifiably or not) that commercial divers have been harvesting there against communal agreement. Seri commercial fishers, in turn, frequently blame outside fishermen, and when enough uproar about such rule-breaking is created within the community, permits to outside fishers are forfeited, despite authorized entrants' protests. Community members ask outsiders to leave the channel or have their fishing gear confiscated, and the overall result is a decrease in fishing effort inside of the channel (Basurto 2005).

Several biological and ecological characteristics also contribute to the maintenance of this social-ecological system. While the Infiernillo Channel is home to the most extensive meadows of eelgrass Zostera marina in western Mexico (Felger and Moser 1985), eelgrasses are almost absent outside of it (Torre-Cosío 2002). At the time of the maximum coverage, Zostera occupies up to $22 \%$ of the channel's bottom, and throughout the 8 months that eelgrasses are present in the channel, distinct $\mathrm{CDH}$ beds are covered and out of reach for harvesting (Torre-Cosío 2002). Scholars have reported that $\mathrm{CDH}$ Atrina tuberculosa and related species' rapid growth and sexual maturation rate at 1 year of age (Niebla-Larreta 2006; Angel-Pérez et al. 2007 ) results in more than $70 \%$ of the harvests in the Infiernillo Channel being more than 1 year old (Basurto 2008), indicating that most of the $\mathrm{CDH}$ have already spawned at least once before being harvested, which, in turn, supports the continued sustainability of the $\mathrm{CDH}$ population. Altogether, the social-ecological factors described above seem to make CDHs more resilient to perturbations or stressing factors than other marine species in which harvesting practices are linked more closely to reproductive behavior.

\section{Methodology}

The system dynamics methodology

System dynamics is an appropriate tool to address the goal of this paper because allows the construction and analysis of mathematical models and simulation scenarios that identify critical feedbacks influencing the system (Costanza and Ruth 1998; Stave 2002). System dynamics has been increasingly used in a wide variety of environmental and resource settings (Cavana and Ford 2004), such as global environmental sustainability (Meadows et al. 2004), water resource planning in irrigation systems (Ostrom 2001), and ecological modeling (Costanza et al. 1993, 2001). A detailed description of system dynamics methodology with special emphasis on social ecological systems is given by Ford (1999) and a very understandable general explanation about how to apply it can be found by Saysel et al. (2002).

\section{Model description}

The basic model is formalized as the simple stock-flow structure (Fig. 2). The complete VENSIM model is 


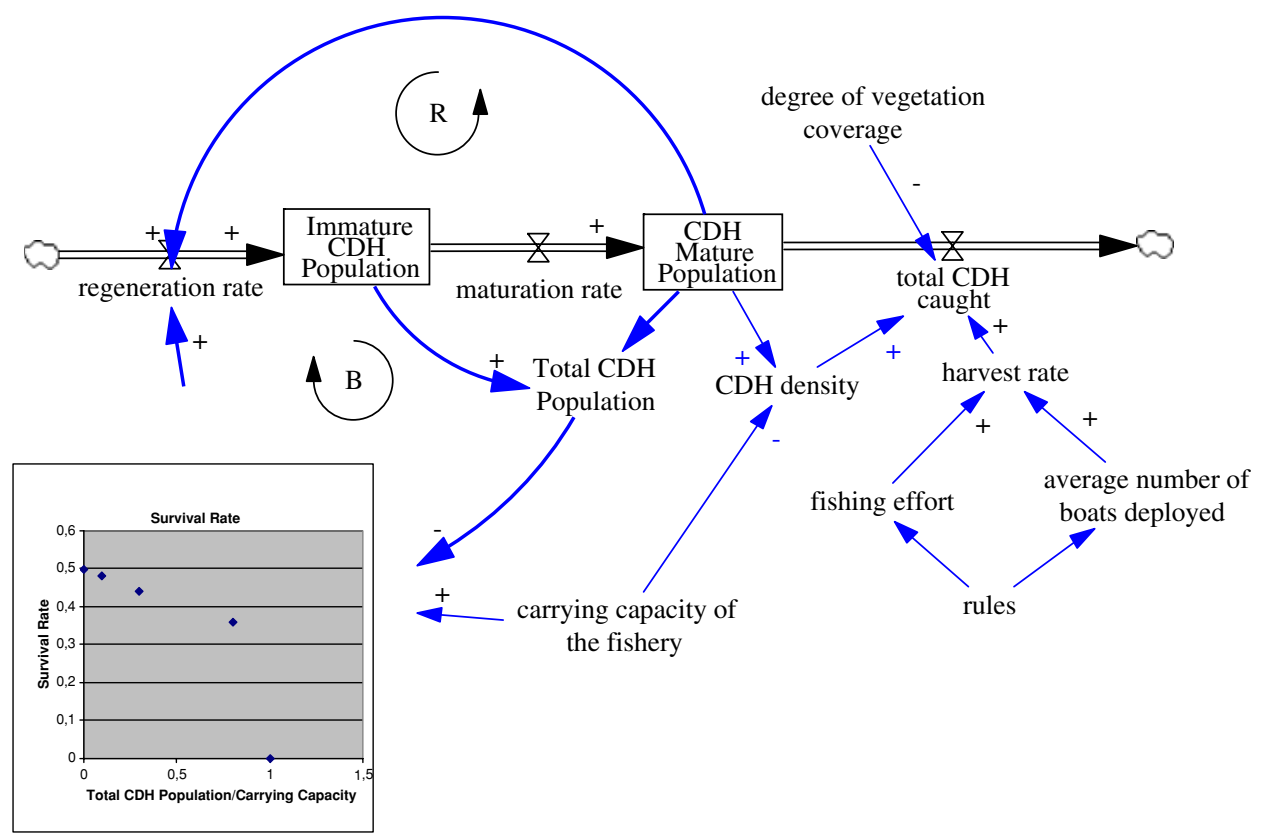

Fig. 2 A simple model for $\mathrm{CDH}$ population dynamics. Variables inside the boxes are the state variables of the system, while the others are either parameters, like the carrying capacity of the fishery, estimated by extrapolating observations in a sample of the total area, or auxiliary variables, like the harvest rate. The harvest rate is given by institutional rules that determine fishing effort, that is, the number the days that fishermen go to sea, and by the capture capacity, given by the average number of boats deployed in the fishery, which also depends on the specific institutional rules adopted by the community. The positive signs indicate there is a direct relationship between the variables and the negative signs an inverse one. Thus, the total amount of $\mathrm{CDH}$ caught increases with the harvest rate and with $\mathrm{CDH}$ density in the channel, and decreases when the size of the area of the channel covered by marine vegetation rises. The mark $R$ indicates the presence of a positive or self-reinforcing loop. Hence, increases (decreases) in $\mathrm{CDH}$ mature population increase (decrease) the

available upon request. In the model, there are two main feedback loops. In the first one, highlighted by the thicker line at the top of the diagram, an increase in the state variable $\mathrm{CDH}$ population increases the regeneration rate and, thus, increases the $\mathrm{CDH}$ population in the next periods. This positive or reinforcing loop also works in the opposite direction: a decrease in the $\mathrm{CDH}$ population leads to further decreases in that population. The second main feedback loop is a negative or balancing one: the increase in the $\mathrm{CDH}$ population leads to a decrease in that population in the future due to the effect of larger populations over the resource base.

This effect is based on the Beverton-Holt equation that is used to model fish populations (Ricker 1975). The equation gives the number of $\mathrm{CDH}$ that survive until reaching the reproductive age as a simple function of the number of $\mathrm{CDH}$, the carrying parameter, and an $S$ parameter, which specifies the rate of adjustment of the births at regeneration rate and, thus, the $\mathrm{CDH}$ mature population in the next period. The mark $B$ indicates the presence of a negative or balancing loop. The regeneration rate, thus, depends on the fertility rate of female $\mathrm{CDH}$ and on the survival rate given by the Beverton-Holt equation: the larger the total $\mathrm{CDH}$ population $(\mathrm{CDH})$ in relation to carrying capacity (CC) on the $x$ axis, the lower the survival rate on the $y$ axis, and the smaller the $\mathrm{CDH}$ population in the next period. The sign of the loop, that is, whether it is of self-reinforcing or balancing type, is obtained by multiplying the signs of the relationships included in the loop. The system may collapse if the flow of total CDH caught exceeds a safety level beyond which the regeneration rate in the next periods will be lower than the total harvests, which leads the selfreinforcing loop (in its collapse mode, in which decreases in the $\mathrm{CDH}$ population lead to further decreases) to dominate the systems' dynamics

very low densities of population. ${ }^{1}$ The time path of the immature $\mathrm{CDH}$ population is then given by the following differential equation:

$\partial($ Immature $\mathrm{CDH}$ population $) / \partial t$

$=$ Regeneration rate - Maturation rate

where

Regeneration rate $_{t}=$ Births $_{t} \times$ Survival rate

and

Survival rate $=$ If total $\mathrm{CDH}$ population

$<$ carrying capacity, $\left[1 /\left(\frac{\text { total } \mathrm{CDH} \text { population }_{t}}{\text { carrying capacity }}+\frac{1}{S}\right)\right], 0$

${ }^{1}$ For modeling purposes, the surviving rate is modeled as an if then else function set at zero when the total $\mathrm{CDH}$ population exceeds the carrying capacity. 
Births $_{(t)}=$ Mature CDH population $_{(t)} \times$ Female percent

$\times$ Fecundity rate/(Reproductive average life)

The differential equation for the $\mathrm{CDH}$ mature population dynamics is as follows:

$\partial(\mathrm{CDH}$ mature population $) / \partial \mathrm{t}$

$=$ Maturation rate - Total $\mathrm{CDH}$ caught

in which

Maturation rate red $_{t+1}=$ delay fixed $\left(\right.$ births $\left._{t}, 1,1000\right)$

Total CDH caught $t_{t}=$ harvest rate $_{t}$

which means that surviving $\mathrm{CDHs}$ will reach the mature cohort after 1 year of its birth, being the initial value of simulation equal to 1,000 entities.

The harvest rate, for simplicity, is given by the equation below:

Harvest rate $_{t}=$ Fishing effort ${ }_{t} \times 365$

$\times$ Number of organisms per boat

$\times$ Average boats $_{t}$

and

Fishing effort ${ }_{t}=$ Rule in use ${ }_{t}$

where the 'fishing effort' is a decision variable varying between 0 and 1 , indicating the percentage of the days of the year that Seri fishermen go to sea. This variable takes into account environmental conditions and the rules that the community has devised to control fishing effort, which result in that fishers harvest CDHs on only $50 \%$ of the days of the year. The capture capacity is given by the 'average number of boats' deployed by the fishermen (which also depends on the rules in use) times the capture capacity per boat (number of organisms per boat). The total harvest, however, depends on the density of $\mathrm{CDH}$ in the channel. The variable $\mathrm{CDH}$ density below incorporates the effect of fishing efficiency: the larger the population of mature organisms density in the channel, the easier it is to find $\mathrm{CDHs}$ with the same fishing effort. The potential mature organisms caught, hence, is given for:

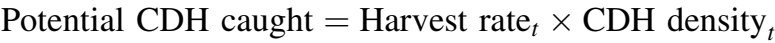

but the effective total $\mathrm{CDH}$ caught is given for:

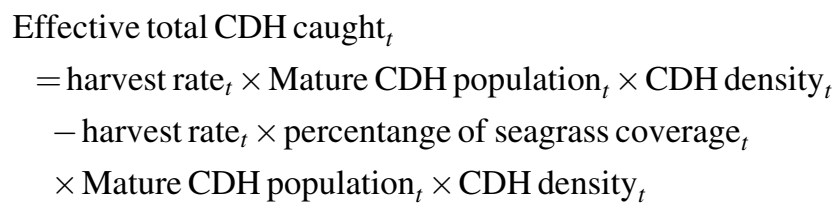

The equation assumes that fishing occurs only in areas of the channel not covered by marine vegetation, hence, we have to subtract from the potential total of $\mathrm{CDH}$ caught the amount which will not be caught due vegetation coverage protection. Field research by Torre-Cosío (2002) and Basurto (2008) reported that, during roughly 8 months of the year, the eelgrass Zostera marina covers $22 \%$ of the Infiernillo Channel's sea bottom, and in the remaining months of the year, the algae Caulerpa spp. covers about $6 \%$.

The stock of CDHs in a particular year refers to the number of $\mathrm{CDH}$ born and entering the mature cohort, and, thus, increasing the size of the stock. The basic dynamics of the system is the following: if too many $\mathrm{CDH}$ are harvested, the sexually mature population will decrease, as will the amount of births in the coming periods. This is a reinforcing process where, if the initial decrease is not very large, it will be checked at some point by the balancing loop, that is, the decrease in population increases the survival rate of juvenile $\mathrm{CDH}$, which stops the decline, stabilizing the mature population at a lower level of $\mathrm{CDH}$. But if the initial decrease surpasses a critical level, the effect of the balancing loop may be not sufficient to compensate for the increase in the harvest rate, which makes the regeneration fall below the harvest rate; henceforth, the system will enter a collapse trajectory. Thus, the loss of resilience of a social-ecological system may be seen as a bifurcation point given by a change in loop dominance. The system is resilient as far as the balancing loop is the dominant one; it will loose resilience when the reinforcing loop (working in its decline mode) becomes dominant. Simulations in the next section provide an illustration of this process.

\section{Simulations}

The parameter values assumed in the simulations below are shown in Table 1.

The values in Table 1 are based on extensive empirical fieldwork unless data were not available, in which case they were roughly estimated. The carrying capacity, for instance, was estimated by extrapolating the amount of $\mathrm{CDH}$ found in a small part of the channel to the total area. The fecundity rate was calculated so that $90 \%$ occupation of the carrying capacity for $\mathrm{CDH}$ could be achieved in the absence of human harvesting. The fecundity rate, in other words, was calibrated in order to solve the following system of equations:

$$
\begin{aligned}
& \text { births }=\text { normal death rate } \\
& \text { births }=\text { mature } \mathrm{CDH} \text { population } \times \text { female percent } \\
& \quad \times \text { fecundity rate } /(\text { reproductive average life }) \\
& \quad \times \text { effect of the population increase } \\
& \text { normal death rate }=\text { mature } \mathrm{CDH} \text { population } / \\
& \quad \text { average lifetime } \\
& \text { mature } \mathrm{CDH} \text { population }=90 \% \text { of the carrying capacity }
\end{aligned}
$$


Table 1 Parameter values for the simulations of the Seri fishery

\begin{tabular}{ll}
\hline Carrying capacity & $\begin{array}{c}24,316 \times 10^{3} \\
\text { organisms }\end{array}$ \\
Female percentage & 0.5 \\
Fecundity rate & 20 organisms \\
Reproductive average life & 9 years \\
$S$ & 0.5 \\
Immature period & 1 year \\
Fishing effort & 0.5 \\
Average number of boats deployed & 13 \\
Number of organisms harvested & 2,160 \\
$\quad$ per boat/day & \\
Percentage of mature organisms/total & 70 \\
$\quad$ organisms harvested & \\
Number of mature organisms per kg & 30 \\
Number of immature organisms per kg & 60 \\
Percentage of the channel protected by & $22 \%$-January/ \\
$\quad$ vegetation coverage & August; \\
& $6 \%$ September/ \\
& December \\
\hline
\end{tabular}

where the effect of the population increase is given by the Beverton-Holt equation, the female percentage is assumed as $50 \%$ of the total population, and the average lifetime and reproductive average life are, respectively, 10 and 1 years.

To place some of the assumptions in perspective, assume that there are initially 20 million adult $\mathrm{CDH}$ in the channel. With $50 \%$ females with a fecundity rate of 20 $\mathrm{CDH}$, the number of $\mathrm{CDH}$ born each year is $10,000,000 \times 20 / 9$, that is 10 million female $\mathrm{CDH}$, times the fecundity rate, divided by the average reproductive life, or 22 million $\mathrm{CDH}$. If the survival rate for high populations (given by the Beverton-Holt equation) is $33 \%$, the number of $\mathrm{CDH}$ that are born and survive each year will be 6.6 million.

If the fishermen fish $50 \%$ of the days of the year, each boat will harvest 2,160 organisms $\times 365 \times 0.5$, which is about $394,200 \mathrm{CDH} /$ year. If about $30 \%$ of the $\mathrm{CDH}$ fished are immature organisms, that amount corresponds to approximately 117,000 and 277,000 immature and mature $\mathrm{CDH}$, respectively. As there are 60 and 30 organisms, respectively, per $\mathrm{kg}$, the total amount of $\mathrm{CDH}$ harvested will be approximately 11 tons per boat/year, or 143 tons for the 13 boats that fish on average in the Infiernillo Channel. If, finally, the vegetal coverage prevents, on average, $17 \%$ of the channel to be exploited during the year, that is, $0.22 \times 8$ months $+0.06 \times 4$ months) $/ 12$, the total $\mathrm{CDH}$ harvested by the Seri during a year will be 119 tons.

But the dynamics of the models can be very complex (and somewhat counterintuitive). For illustrating that complexity, let's suppose that the Seri fishermen are presently deploying 13 boats, fishing during half of the
$\mathrm{CDH}$

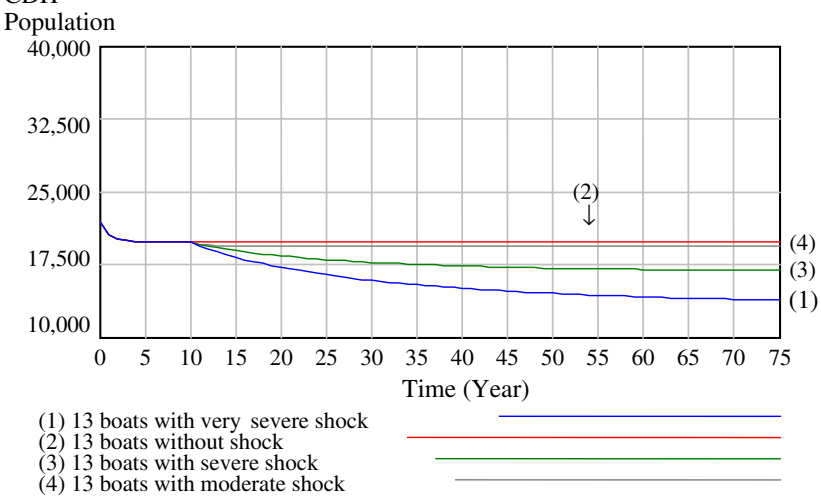

Fig. 3 Total CDH population in four different environmental shock scenarios. The 13 boats with very severe shock scenario is modeled as the complete disappearance of the vegetation coverage from year 5 onwards, which would increase harvesting rates correspondingly. The effect of environmental shocks like that would reduce the equilibrium $\mathrm{CDH}$ population, but would not lead the system to collapse altogether. The 13 boats with severe shock scenario and the 13 boats with moderate shock scenario assume, respectively, 50 and $25 \%$ decreases in the vegetation coverage

days of the year, and that the initial population of $\mathrm{CDH}$ in the fishery is at $90 \%$ of its carrying capacity. (This initial utilization level is not important for whichever values are assumed for the initial populations. Since the right proportion between immature and mature $\mathrm{CDH}$ are observed, ${ }^{2}$ the total $\mathrm{CDH}$ population converges for a value of approximately $80 \%$ of the carrying capacity in the long term.)

Let's examine first the effect of surprises such as an environmental shock produced by a permanent reduction of the vegetal coverage in the channel. For simplicity sake, let's suppose four different scenarios (Fig. 3). In the 13 boats with very severe environmental shock scenario from year 5 of the simulation onwards, the degree of severity of the environmental shock is modeled as the complete and permanent disappearance of the vegetal coverage. The other scenarios assume that natural protection is 75 and $50 \%$ lower than its original value depicted in the 13 boats without shock scenario. It is a small wonder that the larger the magnitude of the shock, the more serious its impact is on the system. In other words, there is an (approximately) linear relation between surprises and their effects upon the system. ${ }^{3}$ The scenario representing a very severe environmental shock with institutional response in Fig. 4 shows that a reduction of about $10 \%$ in the fishing effort would be

\footnotetext{
That is, the proportion of 1-9 following the age cohorts.

${ }^{3}$ For example, the collapse of the Maya civilization is usually explained by the very severe droughts that happened in the late classic period (Gill 2000). But if the Maya had been able to cope with the droughts, by reducing water consumption, the Maya civilization could have, in theory, survived for many more years.
} 


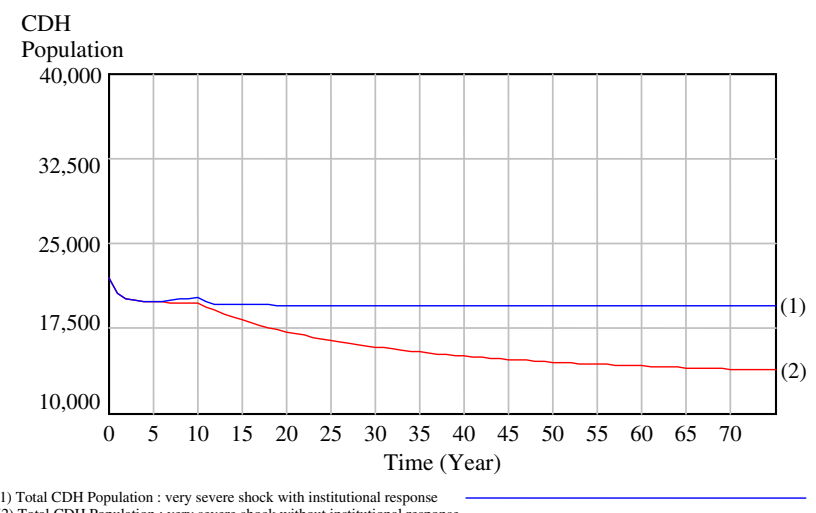

(1) Total CDH Population : very severe shock with institutional response
(2) Total CDH Population : very severe shock without institutional response

Fig. 4 The effect of institutional responses in counteracting environmental shocks. The reduction of about $10 \%$ in the fishing effort represented in the very severe shock with institutional response scenario - that is, with a reduction in the number of days that the fishermen go to sea-would be enough to drive the system back to the pre-collapse situation

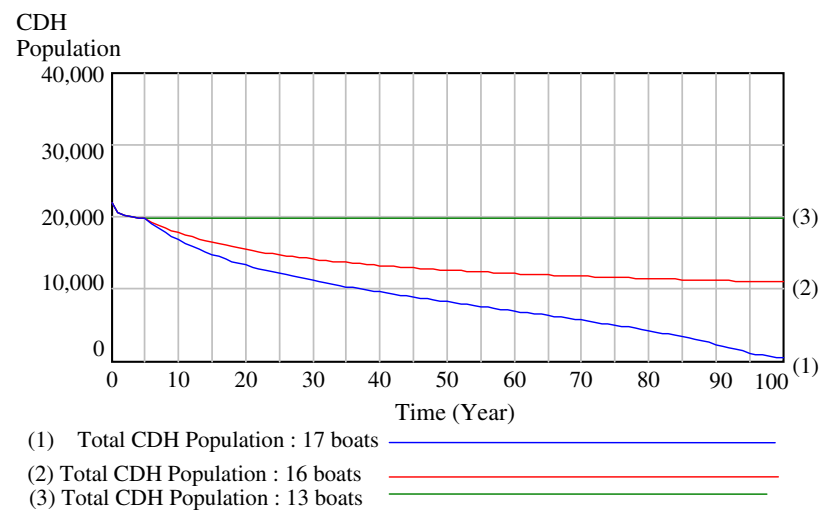

Fig. 5 The effect of quantities on Seri fishery's resilience. The quantity effect in action: the increase of only one boat to the Seri fleet - 16 to 17 boats-may lead the system to collapse, that is, the $\mathrm{CDH}$ population to go commercially extinct. When there is no human harvesting-zero boats scenario-the population converges to the carrying capacity, as it will be shown in Fig. 7

enough to drive the system back to the pre-collapse situation. In other words, that is exactly what an intuitive view about resilience would suggest. Unexpected large shocks may severely disturb the system when not followed by adequate institutional responses. Thus, the question is how do societies cope with surprises? If they are able to answer appropriately to new and unexpected challenges, the system will be resilient. If not, the system will become less productive and eventually collapse.

But the effect of non-novelty stressors on resilience is more subtle. In order to see that, let's suppose a scenario with 16 boats labeled as 16 boats run in Fig. 5-where three additional boats owned by Kino Viejo (KV) fishermen gained access to the channel and are added to the 13 boats traditionally deployed by the Seri fishery starting from year 5 of the simulation. As it would be expected, the effect is a reduction in the $\mathrm{CDH}$ population in the channel to approximately $50 \%$ of the value obtained in the first scenario with 13 boats. But observe that the system has not collapsed; it was able to keep its integrity, although at a lower level of efficiency.

Something totally different happens when one more boat is added: the 17 boats scenario. Just one additional boat is enough to make the fishery enter into a collapse trajectory. Why does that happen?

The answer is not at all intuitive: in passing the threshold of 16 boats, the reinforcing loop R (in Fig. 2), working in its decline mode, starts dominating the system's dynamics. The smaller stock of mature $\mathrm{CDH}$ remaining after the increase in the harvest rate implies, henceforth, less births and, therefore, lower regeneration rates. This important characteristic of the reinforcing loop being able to work in one of two directions is critical for understanding why small variations in exogenous variables such as the one that we are assuming here is able to force the system to enter into a collapse path. Before reaching this tipping point, the system's dynamics was dominated by the balancing loop (B): the increase in the harvest rate decreased the $\mathrm{CDH}$ mature population and the regeneration rate due to the fall in the number of $\mathrm{CDH}$ being born. The decrease in the $\mathrm{CDH}$ population, however, decreased the pressure over the environment as well, which increased the number of births, equilibrating the system in a new (lower) level of activity. After crossing this critical threshold, therefore, a change in loop dominance occurs and the system starts to be dominated by the reinforcing loop (R). That's why the new equilibrium is an unstable one. Once the threshold is crossed, small deviations from the new equilibrium, such as the decrease in the stock of $\mathrm{CDH}$ mature population caused by the increase of adding one boat to the fleet, are amplified.

At the unstable equilibrium of 16 boats, for the same reason, the fishery is much more vulnerable to environmental shocks such as a decrease in the channel vegetal coverage, which, as mentioned above, is a kind of natural protection for $\mathrm{CDH}$ because it prevents fishing in the area covered. The two graphs in Fig. 6 depict the sensitivity of the solutions to random variations in the vegetal coverage. In both cases, we performed Monte-Carlo simulations for the $\mathrm{CDH}$ total population, varying randomly the parameters for vegetal coverage in the 13 and 16 boats scenarios, respectively. The conclusion is that, when the fishery is at its instability tipping point, variations in environmental conditions that could have been perfectly bearable in other circumstances can drive the system to collapse. This is exactly what several authors have pointed out. The progressive increase in the resource usage can make the system more vulnerable even to small environmental shocks (e.g., Carpenter et al. 2001; Diamond 2005). 


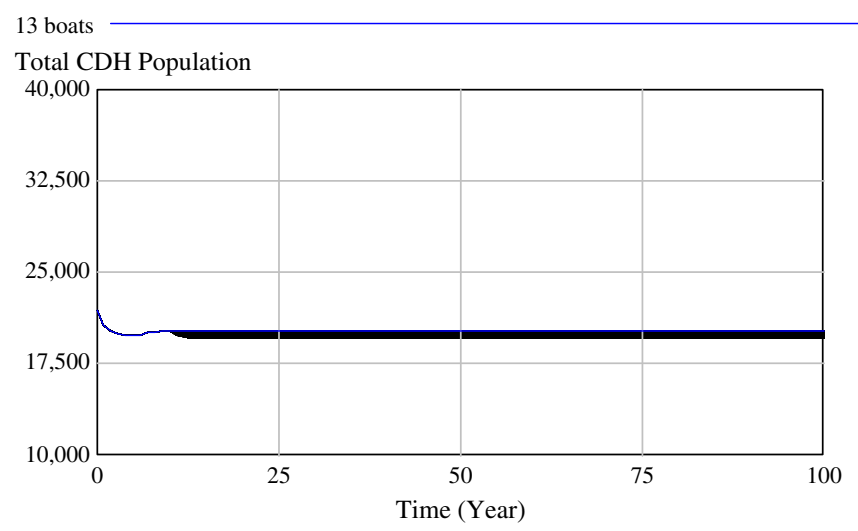

Fig. 6 Sensitivity of the fishery's dynamics to variations in environmental conditions. In the 17 boats scenario on the right side, the system becomes more vulnerable to environmental shocks compared

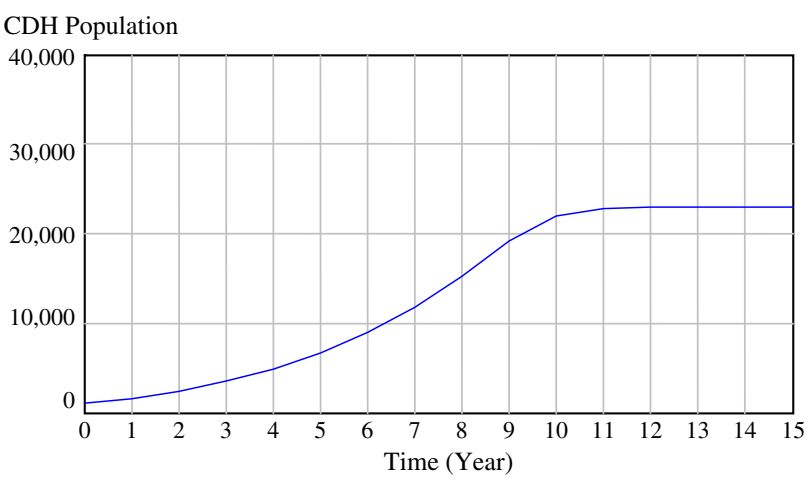

Total CDH Population

Fig. $7 \mathrm{CDH}$ population dynamics without human harvesting. In the absence of human harvesting, the $\mathrm{CDH}$ population would follow the traditional logistic pattern presented by all biological populations, stabilizing itself at the carrying capacity level

The dynamics of a social-ecological system such as the Seri fishery described above may be generalized in the following way. In the absence of any human harvesting, the $\mathrm{CDH}$ population would grow from low levels of density until the carrying capacity was totally occupied, following the logistic pattern predicted by the Beverton-Holt equation, as depicted in Fig. 7.

Incorporating the anthropogenic factor, however, makes for more complex dynamics. As far as the harvest rate is concerned, in Fig. 8, it is smaller than the fishery's regrowth rate. The stock of mature $\mathrm{CDH}$ population increases and so does the $\mathrm{CDH}$ total population. This happens in the region of the graph where the re-growth curve is above the harvest rate curve. ${ }^{4}$ However, if initial conditions for

\footnotetext{
4 The re-growth curve represents the logistic pattern predicted by the Beverton-Holt equation, presented in Fig. 7: stocks grow fast at the beginning and slower for large populations. The harvest rate curve represents the amount of $\mathrm{CDH}$ harvested by the fleet deployed operating at full capacity.
}

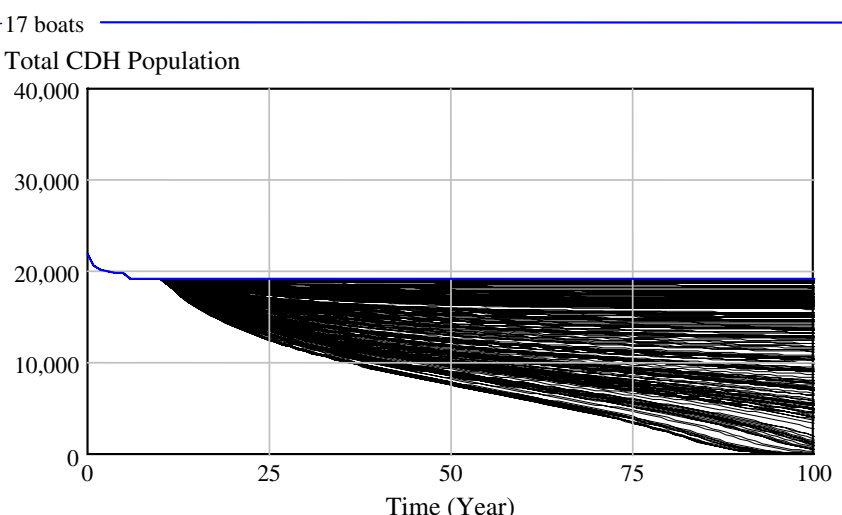

to the 13 boats scenario. A reduction in the marine vegetation coverage may lead the $\mathrm{CDH}$ population to disappear altogether

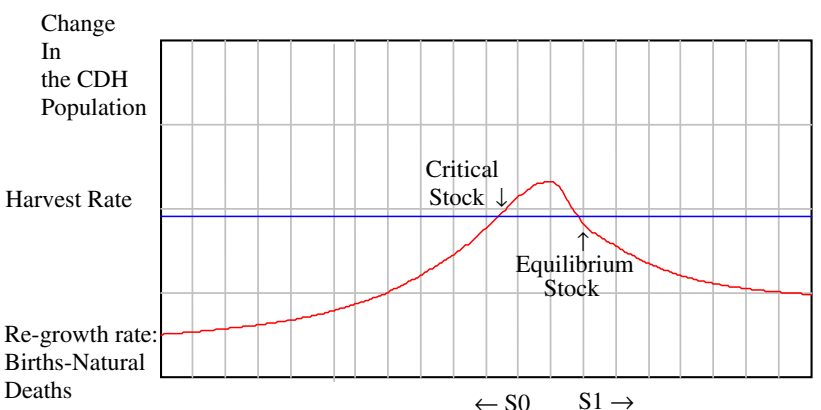

Fig. 8 Tipping points in $\mathrm{CDH}$ population dynamics. If the $\mathrm{CDH}$ population falls below the critical stock, the harvest rate becomes larger than the re-growth rate and the next period will be lower, leading the stock to decrease further. Once the system crosses that tipping point, therefore, the system enters an endogenous trajectory of collapse

simulation change, for instance, if the mature $\mathrm{CDH}$ population fell below a certain critical level defined as a tipping point in response to a environmental shock, the tendency would be towards instability, that is, the $\mathrm{CDH}$ population will continue to fall in the following periods. The reason being that, below the tipping point, the system's re-growth rate will be smaller than the harvest rate of $\mathrm{CDH}$.

In Fig. 9, a scenario representing the "16 boats threshold crossing" is represented in order to help understand the dynamics involved. Suppose that Seri fishermen are initially harvesting only part of the stock of $\mathrm{CDH}$ available in the channel and deploying 13 boats. The stock of $\mathrm{CDH}$ at this time is, say, at the level $S_{t}$. Now, suppose that the number of boats deployed by the fishermen increases, from 13 to 16 boats. This second situation is represented by an upward shifting of the harvest rate curve and the new equilibrium level will be at $S_{t+1}$.

This new equilibrium level could, in theory, be sustained, although Seri fishers have now become more vulnerable to environmental shocks. But suppose that, due to 


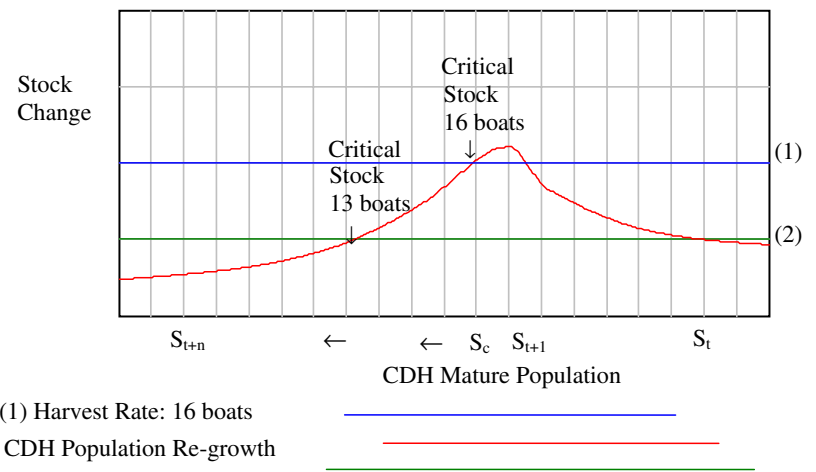

2) Harvest Rate: 13 boats

Fig. 9 The dynamics of overexploitation in the Seri fishery. A larger fleet implies that the system will become less resilient to shocks. If 16 boats are deployed, a decrease in the marine vegetation coverage, which would allow fishermen to catch more $\mathrm{CDH}$ in a given year, would reduce the stock of $\mathrm{CDH}$ in the next year to below $S_{\mathrm{c}}$, leading the system to be dominated by the self-reinforcing loop in its collapse mode. If only 13 boats are deployed, however, $S_{\mathrm{c}}$ is not a tipping point of the system; in the next period, the population will increase again because re-growth, that is, the regeneration rate, will be larger than the harvest rate

the presence of one unnoticed boat for the neighboring town of $\mathrm{KV}$, the population of $\mathrm{CDH}$ falls below the critical stock $\left(S_{\mathrm{c}}\right)$. In this case, the $\mathrm{CDH}$ population would enter a collapsing trajectory merely due to the quantity effect, exactly as it was shown in the simulation exercise for " 17 boats" in Fig. 5.

\section{Discussion}

Our analyses indicate that an incremental effect may be a major cause of loss of resilience of common-pool resource systems like the Seri CDH fishery. Systems facing an ongoing stream of routine stressors have thresholds or tipping points beyond which performance rapidly collapses. We showed that this happens because, at those thresholds, changes in looping dominance occur. For lower intensities of stress, balancing loops tend to lead the system to an equilibrium state. For higher levels of stress, the system may be pushed away from the equilibrium and reinforcing loops begin to dominate the system's dynamics.

While understanding loss of resilience crises requires considering both surprises and the incremental effects of routine stressors that a particular system can be subject to, crises induced mainly by the accumulation of routine stressors are quite different to crises induced mainly by surprises.

A typical surprise-induced crisis results from events for which a social-ecological system does not have an appropriate response within its repertoire, for instance, a temporary environmental shock that would impair the

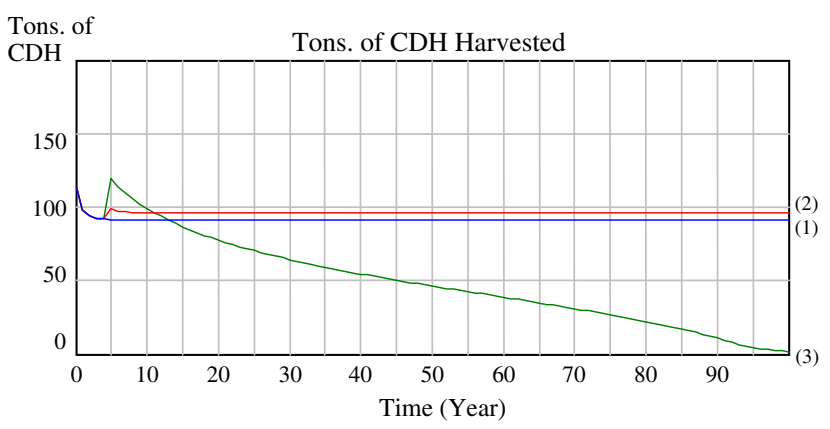

(1) 13 boats

(2) 14 boats

(3) 17 boats

Fig. 10 Time signature for quantity-induced crises. A possible time signature for quantity-induced crises in fishing common-pool resource systems is a temporal increase in harvesting (around year 5 in the figure), followed by a collapse in resource availability

buffering role played by the vegetal coverage in the Infiernillo Channel. Incremental effects-induced crises are more difficult to recognize than surprise-induced crises, given that change might be unnoticeable or subtle until it reaches a tipping point, where the system flips to a different state altogether. In order to address this issue, researchers would need to be able to conceptualize and measure resilience as the distance of a particular social-ecological system from its tipping point, so that agents could be able to prevent the crisis before it happens. Identifying a priori the vulnerability of the system to an incremental effectsinduced crises is extremely difficult however (Moxnes 2000). Initially, the amount of CDH harvested increases in response to increasing the number of boats, which decrease the population of mature $\mathrm{CDH}$. But unlike situations where the balancing loop dominates the system dynamics, when it crosses its tipping point, the decrease in $\mathrm{CDH}$ mature population is large enough to make the reinforcing loop the dominant one. Hence, rather than stabilizing, the population and harvest rate start to decrease along a self-reinforcing path. Thus, our analysis suggests that this particular quantity-induced crisis may have an identifiable time signature: a rising level of resource extraction-tons of $\mathrm{CDH}$ harvested-followed by a sharp decline, as shown in the "17 boats" scenario in Fig. 10.

The explanation for the change in loop dominance is simply that the inclusion of one additional boat in year 5 of the simulation allows the death rate to consistently overcome the birth rate, henceforth, pushing the system into an endogenous (self-reinforcing) decline trajectory, as shown in Fig. 11.

More often than not, users of a common-pool resource system fail to recognize that their systems are falling into a collapse trajectory (Moxnes 2000). The experience that people have before crossing the tipping point is likely to misguide them when the crisis arrives. After all, things 


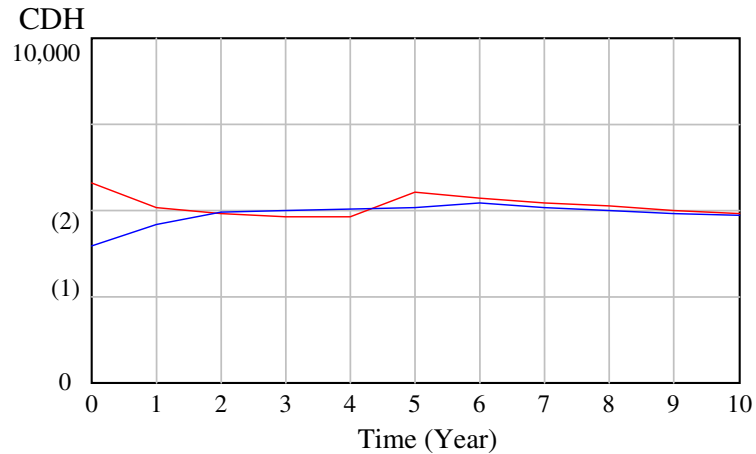

(1) births : 16 boats

(2) total deaths : 16 boats

Fig. 11 Birth and death flows for the $\mathrm{CDH}$ population in two scenarios (16 and 17 boats). In the second graph (17 boats scenario), the death flow (CDH caught) becomes consistently larger than the

went well before and apparently nothing new has actually happened to suggest that they must change their behavior. Nevertheless, perhaps the understanding that small changes may, in certain circumstances, lead to drastic changes in the environment may help common-pool resource users better understand the dynamics and build preventive measures with which they can maintain their social-ecological systems.

Acknowledgments We remain grateful to the visiting scholar program of the Workshop in Political Theory and Policy Analysis at Indiana University. An earlier version of this paper was presented at the Resilience 2008 Conference in Stockholm, Sweden, 14-17 April 2008. We also acknowledge the Coordination Agency for Improvement of Teaching Personnel (CAPES) of the Brazilian Government and the Mexican National Council for Science and Technology (CONACyT) for their financial support. David Price provided excellent editorial support.

\section{References}

Adger WN (2000) Social and ecological resilience: are they related? Prog Hum Geogr 24(3):347-364. doi:10.1191/03091320070 1540465

Alexander P (1977) South Sri Lanka sea tenure. Ethnology 16:231255

Anderies JM (2000) On modeling human behavior and institutions in simple ecological economic systems. Ecol Econ 35:393-412. doi:10.1016/S0921-8009(00)00221-4

Angel-Pérez C, Serrano-Guzmán SJ, Ahumada-Sempoal MA (2007) Ciclo reproductivo del molusco Atrina maura (Pterioidea: Pinnidae) en un sistema lagunar costero, al sur del Pacífico tropical mexicano. Rev Biol Trop 55(3/4):839-852

Basurto X (2005) How locally designed access and use controls can prevent the tragedy of the commons in a Mexican small-scale fishing community. J Soc Nat Res 18:643-659. doi:10.1080/ 08941920590959631

Basurto X (2006) Commercial diving and the Callo de Hacha fishery in Seri territory. J Southwest 48(2):189-209 b

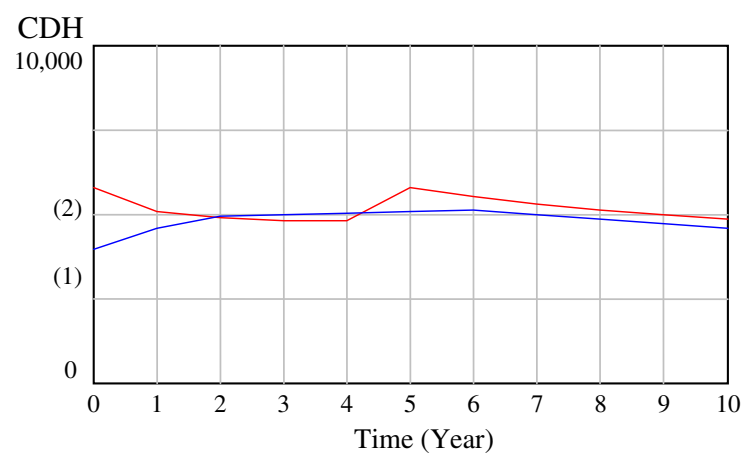

(1) births : 17 boats

(2) total deaths : 17 boats

birth flow (regeneration rate), which explains why the system collapses when a critical threshold is crossed

Basurto X (2008) Biological and ecological mechanisms supporting marine self-governance: the Seri callo de hacha fishery in Mexico. Ecol Soc 13(2):20. Available online at: http://www. ecologyandsociety.org/vol13/iss2/art20/

Basurto X, Ostrom E (2009) Beyond the tragedy of the commons economia delle fonti di energia e dell' ambiente. Italian J 52(1) (in press)

Brander JA, Taylor MS (1998) The simple economics of Easter Island: a Ricardo-Malthus model of renewable resource use. Am Econ Rev 88(1):119-138

Carpenter S, Gunderson L (2001) Coping with collapse: ecological and social dynamics in ecosystem management. BioScience 51(6):451-457. doi:10.1641/0006-3568(2001)051[0451: CWCEAS $] 2.0 . \mathrm{CO} ; 2$

Carpenter S, Walker B, Anderies JM, Abel N (2001) From metaphor to measurement: resilience of what to what? Ecosystems 4(8):765-781. doi:10.1007/s10021-001-0045-9

Cavana RY, Ford A (2004) Environmental and resource systems: editors' introduction. Syst Dyn Rev 20(2):89-98. doi:10.1002/ sdr.293

Costanza R, Ruth M (1998) Using dynamic modeling to scope environmental problems and build consensus. Environ Manage 22(2):183-195. doi:10.1007/s002679900095

Costanza R, Wainger L, Folke C, Mäler K-G (1993) Modeling complex ecological economic systems. Bioscience 43(8):545555

Costanza R, Low BS, Ostrom E, Wilson J (2001) Institutions, ecosystems, and sustainability. Lewis Publishers, Boca Raton, $270 \mathrm{pp}$

Diamond J (2005) Collapse: how societies choose to fail or succeed. Viking, New York

Felger RS, Moser MB (1985) People of the desert and sea: ethnobotany of the Seri Indians. University of Arizona Press, Tucson

Folke C, Carpenter S, Elmqvist T, Gunderson L, Holling CS, Walker B (2002) Resilience and sustainable development: building adaptive capacity in a world of transformations. Ambio 31(5):437-440

Ford A (1999) Modeling the environment, an introduction to system dynamics models of environmental systems. Island Press, Washington

Gill RB (2000) The great Maya droughts: water, life, and death. University of New Mexico Press, Albuquerque 
Hilborn R, Branch TA, Ernst B, Magnussson A, Minte-Vera MD, Scheuerell MD, Valero JL (2003) State of the world's fisheries. Annu Rev Environ Resour 28:359-399

Holling CS (1973) Resilience and stability of ecological systems. Annu Rev Ecol Syst 4:1-23

Holling CS, Schindler DW, Walker BW, Roughgarden J (1995) Biodiversity in the functioning of ecosystems: an ecological synthesis. In: Perrings C, Maler K, Folke C, Holling CS, Jansson B (eds) Biodiversity loss. Cambridge University Press, Cambridge

Jackson JBC, Kirby MX, Berger WH, Bjorndal KA, Botsford LW, Bourque BJ, Bradbury RH, Cooke R, Erlandson J, Estes JA, Hughes TP, Kidwell S, Lange CB, Lenihan HS, Pandolfi JM, Peterson CH, Steneck RS, Tegner MJ, Warner RR (2001) Historical overfishing and the recent collapse of coastal ecosystems. Science 293:629-638. doi:10.1126/science.1059199

Meadows DH, Meadows DL, Randers J (2004) Limits to growth: the 30-year update. Chelsea Green Publishing Company, Vermont

Morecroft J (2007) Strategic modelling and business dynamics-a feedback systems approach. Wiley, West Sussex

Moreno C, Torre J, Bourillón L, Durazo M, Weaver AH, Barraza R, Castro R (2005) Estudio y evaluación de la pesquería de callo de hacha (Atrina tuberculosa) en la Región de Bahía de Kino, Sonora y Recomendaciones para su Manejo. Comunidad y Biodiversidad, AC Reporte interno. Available online at: http://www. cobi.org. $\mathrm{mx} /$ index.php?pag=publicaciones\&idioma $=\mathrm{esp}$

Moxnes E (2000) Not only the tragedy of the commons: misperceptions of feedback and policies for sustainable development. Syst Dyn Rev 16(4):325-348. doi:10.1002/sdr.201

Myers RA, Worm B (2003) Rapid worldwide depletion of predatory fish communities. Nature 423:280-283

Niebla-Larreta JL (2006) Maduración, desove y desarrollo larvario del callo de hacha, Atrina tuberculosa (Sowerby, 1835) bajo condiciones de laboratorio. Thesis. Universidad de Sonora, México
Ostrom E (2001) Reformulating the commons. In: Burger J, Ostrom E, Norgaard RB, Policansky D, Goldstein BD (eds) Protecting the commons. a framework for resource management in the Americas. Island Press, Washington

Perrings C (1998) Introduction: resilience and sustainability. Environ Dev Econ 3:221-262

Randers J (2007) The emergence of Limits to Growth Scenario 2: the pollution crisis. In: Proceedings of the 25th International Conference of the System Dynamics Society, Boston, Massachusetts, July/August 2007

Ricker WE (1975) Computation and interpretation of biological statistics of fish populations. Bulletin 191, Department of Environment, Fisheries and Marine Service, Ottawa

Rudolph JW, Repenning NP (2002) Disaster dynamics: understanding the role of quantity in organizational collapse. Adm Sci Q 47(1):1-30

Salas S, Chuenpagdee R, Seijo JC, Charles A (2007) Challenges in the assessment and management of small-scale fisheries in Latin America and the Caribbean. Fish Res 87:5-16

Saysel A, Barlas Y, Yenigün O (2002) Environmental sustainability in an agricultural development project: a system dynamics approach. J Environ Manage 64:247-260. doi:10.1006/jema. 2001.0488

Stave K (2002) Using system dynamics to improve public participation in environmental decisions. Syst Dyn Rev 18:139-167. doi: $10.1002 /$ sdr.237

Sterman J (2000) Business dynamics: systems thinking and modeling for a complex world. Irwin/McGraw-Hill, Boston

Torre-Cosío J (2002) Inventory, monitoring and impact assessment of marine biodiversity in the Seri Indian territory, Gulf of California, México. Dissertation, University of Arizona, Tucson

Weiss H, Bradley R (2001) What drives societal collapse? Science 291(5504):609-610 (new series). doi:10.1126/science.1058775 